\title{
Determinants of operative mortality in valvular heart surgery
}

\author{
J. Scott Rankin, MD, a Bradley G. Hammill, MS, ${ }^{b, c}$ T. Bruce Ferguson, Jr, MD, Donald D. Glower, MD, ${ }^{b}$ \\ Sean M. O'Brien, PhD, ${ }^{\text {b,c }}$ Elizabeth R. DeLong, $\mathrm{PhD}^{\mathrm{b}, \mathrm{c}}$ Eric D. Peterson, MD, MPH, ${ }^{\mathrm{b}, \mathrm{c}}$ and Fred H. Edwards, MD
}

From Vanderbilt University, Nashville, Tenn ${ }^{\text {a }}$; Duke University Medical Center, Durham, $\mathrm{NC}^{\mathrm{b}}$; Society of Thoracic Surgeons Adult Cardiac Surgery Database, Durham, $\mathrm{NC}^{\mathrm{c}}$; Louisiana State University, New Orleans, $\mathrm{La}^{\mathrm{d}}$; and University of Florida, Jacksonville, Fla.

Read at the Thirty-first Annual Meeting of The Western Thoracic Surgical Association, Victoria, BC, Canada, June 22-25, 2005.

Received for publication July 7, 2005; revisions received Oct 10, 2005; accepted for publication Oct 20, 2005.

Address for reprints: J. Scott Rankin, MD, 2400 Patterson St, Suite 103, Nashville, TN 37203 (E-mail: jsrankinmd@cs.com).

J Thorac Cardiovasc Surg 2006;131:547-57

$0022-5223 / \$ 32.00$

Copyright $(9) 2006$ by The American Association for Thoracic Surgery

doi:10.1016/j.jtcvs.2005.10.041
Objective: In some respects, outcome reporting in valvular surgery has been hampered by focusing on specific populations, reluctance to publish high-risk subgroups, and possibly skewed or inadequate samples. The goal of this study was to evaluate risk factors for operative mortality comprehensively across the entire spectrum of cardiac valvular procedures over the past decade.

Methods: All 409,904 valve procedures in the Society of Thoracic Surgeons database performed between 1994 and 2003 were assessed, and Society of Thoracic Surgeons preoperative and operative variables were related to operative mortality by using a multivariable logistic regression model. Data were greater than $95 \%$ complete, and the relative importance of relevant risk factors was determined by ranking odds ratios. The analysis had a high predictive power, with a $\mathrm{C}$ statistic of 0.735 .

Results: In the model, 19 variables independently influenced operative mortality (all $P<.01$ ). The most significant was nonelective (acute) presentation (odds ratios, 2.11 ), followed by advanced age (odds ratios, 1.88), reoperation (odds ratios, 1.61), endocarditis (odds ratios, 1.59), and coronary disease (odds ratios, 1.58). Generally, valve replacement was associated with higher mortality than repair (odds ratios, 1.52). Overall, female gender was very important (odds ratios, 1.37), and earlier year of operation increased risk (odds ratios, 1.34), implying improving outcomes over time. Although any single comorbidity, on average, was only moderately contributory (odds ratios, 1.19), specific comorbidities, such as renal failure, or multiple comorbidities in a given patient could be very significant. Aortic root reconstruction carried the highest risk (odds ratios, 2.78), followed by tricuspid valve surgery (odds ratios, 2.26), multiple valve procedures (odds ratios, 2.06), and then isolated mitral (odds ratios, 1.47), pulmonic (odds ratios, 1.29), and aortic (reference procedure) operations. Reduced ejection fraction and severity of valve lesion were relatively less important (odds ratios, 1.34 and 0.83 , respectively).

Conclusions: These data illustrate the significance of acute presentation in determining operative risk, and earlier surgical intervention under elective conditions might be emphasized for all types of significant valve lesions. Because aortic root reconstruction doubles mortality compared with simple aortic valve procedures, root replacement should be reserved for specific root pathology. Finally, issues related to reoperation, endocarditis, valve repair, gender, and the various procedures deserve more detailed examination.

$\mathrm{S}$ cientific understanding of how baseline patient variables influence operative mortality in cardiac valvular surgery may have been limited by several factors. Most studies have reviewed small series from single centers and have focused on highly specific and usually low-risk subgroups. Complex valvular procedures are not available in sufficient numbers in most hospitals to allow a comprehensive analysis, and because the more complicated cases tend to have 


\section{Abbreviations and Acronyms}

$\mathrm{IABP}=$ intra-aortic balloon pumping

$\mathrm{LV}=$ left ventricular

$\mathrm{OR}=$ odds ratio

STS $=$ Society of Thoracic Surgeons

higher operative mortalities, many investigators may have been reluctant to publish high-mortality data from complex categories. Confusion occasionally has existed regarding patient classification, and analyses sometimes have been so detailed as to limit clinical utility. Finally, results tend to change over time, and data regarding contemporary outcomes, as well as how prognosis has evolved in recent years, would be useful. As a result of all these issues, current prognostic effects of adverse baseline characteristics, such as advanced age, left ventricular (LV) dysfunction, and acute presentation, are poorly understood, especially as related to the entire spectrum of valve surgery. For example, one recent series of mitral valve repairs for ischemic mitral regurgitation found that severe LV dysfunction was no longer a prognostic factor. ${ }^{1}$ Such a finding could be spurious because of limited sample size, focus on one procedure, or assessment from a single center, the results of which might not be representative. The goal of the present study was to clarify this topic by generating a simple but comprehensive risk factor analysis of operative mortality in the entire Society of Thoracic Surgeons (STS) valve surgery registry. Because many centers are represented and because all valvular procedures are present in ample numbers, it was anticipated that a more complete view of contemporary valve surgery might be obtained.

\section{Patients and Methods}

\section{Data Source}

The STS national database was established in 1989 by North American heart surgeons to collect and assess cardiac surgical results in a valid and consistent manner., ${ }^{2,3}$ The STS database currently records the results of more than $70 \%$ of US adult cardiac surgical procedures annually. Clinical patient data are entered at sites using uniform definitions and certified software systems. Detailed definitions for preoperative risk factors, as well as complications, have been established by the STS and can be viewed online (http://www.sts.org). Data from individual centers are harvested semiannually and sent to the STS data warehouse and analysis center at the Duke Clinical Research Institute. A series of data quality checks are performed before data are aggregated into the national sample. Since 1994, the variables entered and definitions used have been changed in minor ways, but for this study, consistent baseline variables were available in every category for the entire 10-year period, with an overall missing rate of $3.85 \%$. The frequency of missing data ranged from $0.0 \%$ for patient gender to $16.5 \%$ for ejection fraction. The accuracy and compa-
TABLE 1. Distribution of valve procedures

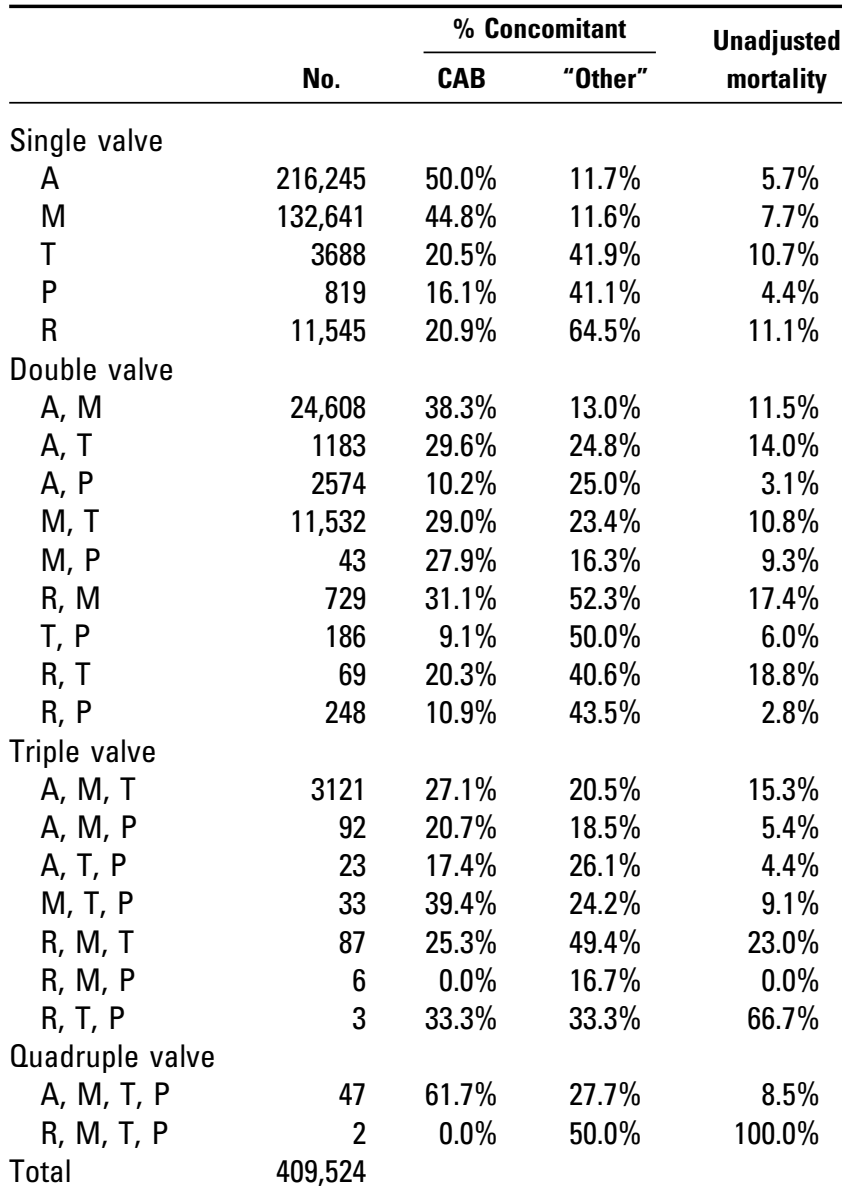

$C A B$, Coronary artery bypass; $A$, aortic valve; $M$, mitral valve; $T$, tricuspid valve; $P$, pulmonic valve; $R$, aortic root reconstruction.

rability of STS results have been confirmed by comparison with other mandatory and audited cardiac databases. ${ }^{4}$

\section{Patient Population}

The population for this study included all 409,904 cardiac valvular procedures in the STS database recorded over the 10-year period between January 1, 1994, and December 31, 2003. From this total, 322 procedures were omitted for "resection of sub-aortic stenosis," and 58 procedures were excluded from one site with unacceptable mortality data, resulting in 409,524 procedures in the study. An additional 424 were missing gender information, leaving 409,100 for inclusion in the statistical model. The individual procedures and sample sizes are shown in Table 1 . The most common operations were isolated aortic valve procedures $(\mathrm{n}=216,245)$, followed by mitral valve procedures $(\mathrm{n}=132,641)$ and then aorticmitral double-valve $(\mathrm{n}=24,607)$, aortic root replacement $(\mathrm{n}=$ $11,545)$, and mitral-tricuspid double-valve $(\mathrm{n}=11,532)$ operations. There were 3121 aortic-mitral-tricuspid triple valves. The incidence of concomitant coronary bypass and "other" procedures also is shown. The types of "other" cases are shown in Table 2. In general, these operations represent a small fraction of the overall group and are composed of highly diverse populations. Ablation 
TABLE 2. Concurrent nonvalvular procedures

\begin{tabular}{lr}
\hline Procedure & No. \\
\hline AICD & 366 \\
ASD & 6188 \\
Batista & 172 \\
Congenital & 2410 \\
Heart transplantation & 130 \\
LVA & 1587 \\
TMR & 321 \\
Pacemaker & 2031 \\
SVR & 178 \\
Cardiac trauma & 212 \\
VSD & 1033 \\
Ascending aortic replacement & 19,143 \\
Carotid endarterectomy & 2257 \\
Other, thoracic & 1932 \\
Other, vascular & 3134 \\
Other, cardiac & 19,386 \\
\hline
\end{tabular}

$A I C D$, Automatic internal cardiac defibrillator; $A S D$, atrial septal defect closure; $L V A$, left ventricular aneurysm resection; $T M R$, transmyocardial revascularization; SVR, surgical ventricular restoration; $V S D$, ventricular septal defect closure.

procedures for atrial fibrillation were not recorded until recently and are omitted. Baseline characteristics of the overall series are presented in Table 3. Preoperative variables remained fairly constant over the decade, except that obesity increased from $6 \%$ to $11 \%$, diabetes increased from $17 \%$ to $23 \%$, hypertension increased from $46 \%$ to $66 \%$, cerebrovascular disease increased from $8 \%$ to $15 \%$, and minor increases were observed in age (65.1 years to 66.3 years, mean), peripheral vascular disease ( $9 \%$ to $13 \%$ ), and renal failure $(6 \%$ to $8 \%)$. Because this study also focused on elective versus acute presentation, baseline data are given additionally for these subgroups.

\section{Selection of Variables for Analysis}

In order to compare quantitatively the relative importance of preoperative patient characteristics in the risk factor analysis, variables were simplified as much as possible and, except for number of comorbidities, were dichotomized so that each could be evaluated as a single degree of freedom. Decisions in this process were made prospectively before the analysis began and were influenced by perceived clinical relevance and the results of previous similar clinical research. The risk factors that were selected included the following: acute presentation (nonelective vs elective); age ( $\geq 70$ years vs $<70$ years); reoperation (yes/no); etiology endocarditis (yes/no); presence of coronary disease, performance of coronary bypass (yes-no); the decision for valve replacement versus repair (for multiple valves, any valve repaired $=$ repair group); New York Heart Association class III or IV congestive heart failure preoperatively (yes/no); gender (female vs male); severe LV dysfunction (ejection fraction $<0.35$ vs $\geq 0.35$ ); earlier year of operation (first 5-year period vs second 5-year period); presence and number of comorbidities (range, 0-10); hemodynamically severe valve lesion (vs mild to moderate); and valve procedure required (referenced to single aortic valve repair or replace- ment procedure): aortic root reconstruction, tricuspid valve procedure, multiple valve procedure ( $\geq 2$ valves operated), mitral valve procedure, pulmonic valve procedure, valve plus other major operation (eg, ascending aortic replacement, LV aneurysm resection, and septal defect closure; see Table 2), and aortic valve procedure. There were 303,043 procedures in the elective group, and the nonelective (acute presentation) group contained 106,481 divided into 3 categories: urgent $(\mathrm{n}=90,956)$, emergency $(\mathrm{n}=$ $12,867)$, and salvage $(n=2658)$. The current STS operational definition of urgent status is as follows: "All of the following conditions are met: Not elective status. Not emergency status. Procedure required during same hospitalization in order to minimize chance of further clinical deterioration. Worsening, sudden chest pain, congestive heart failure, acute myocardial infarction, precarious anatomy, IABP, unstable angina with intravenous nitroglycerin or rest angina may be included." The definition for emergency is as follows: "The patient's clinical status includes any of the following: Ischemic dysfunction: 1. Ongoing ischemia including resting angina despite maximal medical therapy (medical and/or IABP); 2. Acute evolving myocardial infarction within 24 hours before surgery; or 3. Pulmonary edema requiring intubation. Mechanical dysfunction (either of the following): 1. Shock with circulatory support; or 2. Shock without circulatory support." The definition for salvage is as follows: "The patient was undergoing cardiopulmonary resuscitation en route to the operating room or prior to anesthesia induction." The STS definition for mortality is death during the same hospitalization as the valve surgery or after discharge but within 30 days of the operation. Again, other definitions are given at http://www.sts.org. In the analysis, comorbidities included morbid obesity (body mass index $\geq 35$ ), smoker, diabetes, renal failure, dialysis, hypertension, hyperlipidemia, immunosuppressive therapy, cerebrovascular disease, and peripheral vascular disease. Missing categoric variables were imputed by assigning the modal value, and missing continuous variables were assigned the median value. Again, less than $5 \%$ of data were missing overall.

\section{Statistical Analysis}

A multivariable logistic regression model was used to quantify the association between each explanatory variable and operative mortality in a manner that partially adjusted for the confounding effects of other variables. The form of the logistic regression equation was as follows:

$$
\log \left\{\frac{\theta_{i}}{1-\theta_{i}}\right\}=\alpha+x_{i}^{\prime} \beta,
$$

where $\theta_{i}$ is the probability of mortality for the $i$ th patient, $\alpha$ is the model intercept term, $\beta$ is the vector of regression parameters, and $\mathrm{x}_{i}$ is the vector of explanatory variables for the $i$ th patient. This type of logistic methodology has been shown to be superior to other techniques for the purpose of risk factor analysis. ${ }^{5,6}$ The magnitude of the effect of each explanatory variable in the logistic model was quantified by using 2 statistics: the odds ratio (OR) and the adjusted mortality difference. The latter is defined as the difference between the average predicted risk of mortality in the study population if each subject had the risk factor in question minus the average predicted risk of mortality in the study population if no subject had the risk factor in question, holding all other 
TABLE 3. Baseline patient characteristics

\begin{tabular}{|c|c|c|c|c|}
\hline Variable & Overall & Elective & Nonelective & $P$ value \\
\hline No. & 409,524 & 303,043 & 106,481 & \\
\hline Age (y) & & & & $<.0001$ \\
\hline Mean & 66.1 & 65.7 & 67.4 & \\
\hline Median & 69.0 & 69.0 & 70.0 & \\
\hline Age $\geq 70 \mathrm{y}$ & $48 \%$ & $47 \%$ & $53 \%$ & $<.0001$ \\
\hline Gender & & & & $<.0001$ \\
\hline Male & $57 \%$ & $57 \%$ & $56 \%$ & \\
\hline Female & $43 \%$ & $43 \%$ & $44 \%$ & \\
\hline Race & & & & $<.0001$ \\
\hline White & $87 \%$ & $87 \%$ & $85 \%$ & \\
\hline Black & $5 \%$ & $5 \%$ & $6 \%$ & \\
\hline Other-unknown & $8 \%$ & $8 \%$ & $8 \%$ & \\
\hline No. of comorbidities & & & & $<.0001$ \\
\hline 0 & $13 \%$ & $14 \%$ & $10 \%$ & \\
\hline 1 & $26 \%$ & $27 \%$ & $22 \%$ & \\
\hline 2 & $27 \%$ & $27 \%$ & $26 \%$ & \\
\hline 3 & $19 \%$ & $18 \%$ & $20 \%$ & \\
\hline 4 & $10 \%$ & $9 \%$ & $12 \%$ & \\
\hline Obesity (BMI >35) & $9 \%$ & $9 \%$ & $9 \%$ & .2706 \\
\hline Smoker & $48 \%$ & $48 \%$ & $50 \%$ & $<.0001$ \\
\hline Current smoker & $14 \%$ & $13 \%$ & $16 \%$ & $<.0001$ \\
\hline Diabetes & $20 \%$ & $18 \%$ & $25 \%$ & $<.0001$ \\
\hline Hyperlipidemia & $37 \%$ & $36 \%$ & $38 \%$ & $<.0001$ \\
\hline Renal failure & $7 \%$ & $5 \%$ & $12 \%$ & $<.0001$ \\
\hline Dialysis-dependent RF & $2 \%$ & $1 \%$ & $3 \%$ & $<.0001$ \\
\hline Last creatinine preoperatively & & & & $<.0001$ \\
\hline Mean & 1.3 & 1.2 & 1.5 & \\
\hline Median & 1.0 & 1.0 & 1.1 & \\
\hline Hypertension & $58 \%$ & $56 \%$ & $62 \%$ & $<.0001$ \\
\hline CVA & $8 \%$ & $7 \%$ & $10 \%$ & $<.0001$ \\
\hline COPD & $13 \%$ & $12 \%$ & $17 \%$ & $<.0001$ \\
\hline Immunosuppressive treatment & $3 \%$ & $2 \%$ & $4 \%$ & $<.0001$ \\
\hline PVD & $12 \%$ & $11 \%$ & $16 \%$ & $<.0001$ \\
\hline CVD & $12 \%$ & $11 \%$ & $15 \%$ & $<.0001$ \\
\hline Prior MI & $19 \%$ & $15 \%$ & $31 \%$ & $<.0001$ \\
\hline MI within $7 \mathrm{~d}$ & $5 \%$ & $2 \%$ & $13 \%$ & \\
\hline MI within 8-21 d & $2 \%$ & $1 \%$ & $4 \%$ & \\
\hline MI within $>21 \mathrm{~d}$ & $11 \%$ & $11 \%$ & $13 \%$ & \\
\hline Reoperation & $19 \%$ & $18 \%$ & $21 \%$ & $<.0001$ \\
\hline Prior $\mathrm{PCl}$ & $7 \%$ & $6 \%$ & $9 \%$ & $<.0001$ \\
\hline Endocarditis & $5 \%$ & $4 \%$ & $9 \%$ & $<.0001$ \\
\hline Any severe lesion & $79 \%$ & $80 \%$ & $75 \%$ & $<.0001$ \\
\hline NYHA class & & & & $<.0001$ \\
\hline I & $10 \%$ & $11 \%$ & $7 \%$ & \\
\hline II & $18 \%$ & $21 \%$ & $10 \%$ & \\
\hline III & $39 \%$ & $41 \%$ & $33 \%$ & \\
\hline IV & $21 \%$ & $14 \%$ & $40 \%$ & \\
\hline $\mathrm{CHF}$ & $34 \%$ & $29 \%$ & $49 \%$ & $<.0001$ \\
\hline Angina type & & & & $<.0001$ \\
\hline No angina & $63 \%$ & $66 \%$ & $53 \%$ & \\
\hline Stable & $22 \%$ & $24 \%$ & $18 \%$ & \\
\hline Unstable & $15 \%$ & $10 \%$ & $29 \%$ & \\
\hline Cardiogenic shock & $3 \%$ & $1 \%$ & $9 \%$ & $<.0001$ \\
\hline
\end{tabular}


TABLE 3. Continued

\begin{tabular}{|c|c|c|c|c|}
\hline Variable & Overall & Elective & Nonelective & $P$ value \\
\hline Resuscitation & $1 \%$ & $0 \%$ & $3 \%$ & $<.0001$ \\
\hline Arrhythmia & $27 \%$ & $26 \%$ & $30 \%$ & $<.0001$ \\
\hline Acuity of presentation & & & & $<.0001$ \\
\hline Elective & $74 \%$ & $100 \%$ & $0 \%$ & \\
\hline Urgent & $22 \%$ & $0 \%$ & $85 \%$ & \\
\hline Emergency & $3 \%$ & $0 \%$ & $12 \%$ & \\
\hline Salvage & $1 \%$ & $0 \%$ & $2 \%$ & \\
\hline PA mean pressure & & & & $<.0001$ \\
\hline Mean & 25.5 & 24.5 & 28.0 & \\
\hline Median & 24.0 & 24.0 & 27.0 & \\
\hline Pulmonary hypertension & $12 \%$ & $11 \%$ & $16 \%$ & $<.0001$ \\
\hline Ejection fraction & & & & $<.0001$ \\
\hline Mean & 0.51 & 0.52 & 0.48 & \\
\hline Median & 0.50 & 0.50 & 0.50 & \\
\hline Ejection fraction $\geq 0.35$ & $89 \%$ & $91 \%$ & $83 \%$ & $<.0001$ \\
\hline No. of diseased vessels & & & & $<.0001$ \\
\hline 0 & $53 \%$ & $56 \%$ & $42 \%$ & \\
\hline 1 & $13 \%$ & $13 \%$ & $12 \%$ & \\
\hline 2 & $13 \%$ & $13 \%$ & $15 \%$ & \\
\hline 3 & $21 \%$ & $18 \%$ & $30 \%$ & \\
\hline Left main disease & $7 \%$ & $5 \%$ & $11 \%$ & $<.0001$ \\
\hline $\begin{array}{l}\text { Any valve replaced } \\
\text { Isolated valve procedure }\end{array}$ & $81 \%$ & $82 \%$ & $79 \%$ & $<.0001$ \\
\hline Aortic & $53 \%$ & $54 \%$ & $49 \%$ & $<.0001$ \\
\hline Mitral & $32 \%$ & $31 \%$ & $35 \%$ & $<.0001$ \\
\hline Tricuspid & $0.90 \%$ & $0.87 \%$ & $1.00 \%$ & .0001 \\
\hline Pulmonic & $0.20 \%$ & $0.23 \%$ & $0.11 \%$ & $<.0001$ \\
\hline Aortic root reconstruction & $3 \%$ & $2 \%$ & $4 \%$ & $<.0001$ \\
\hline Multiple valve procedure & $10.89 \%$ & $10.76 \%$ & $11.24 \%$ & $<.0001$ \\
\hline Concurrent $\mathrm{CAB}$ & $46 \%$ & $42 \%$ & $56 \%$ & $<.0001$ \\
\hline $\begin{array}{c}\text { Concurrent non-CAB } \\
\text { procedure }\end{array}$ & $14 \%$ & $13 \%$ & $17 \%$ & $<.0001$ \\
\hline
\end{tabular}

$B M I$, Body mass index; $R F$, renal failure; $C V A$, cerebral vascular accident; $C O P D$, chronic obstructive pulmonary disease; $P V D$, peripheral vascular disease; $C V D$, cerebral vascular disease; $M I$, myocardial infarction; $P C I$, percutaneous coronary intervention; NYHA, New York Heart Association; CHF, congestive heart failure; $P A$, pulmonary artery; $C A B$, coronary artery bypass.

variables constant. Independent effects of individual variables on mortality were assessed by comparing ORs. To examine differences in patient characteristics between elective and acute presentation groups, $\chi^{2}$ statistics were used for categoric variables, and Wilcoxon rank sum statistics were used for continuous variables. All analyses were performed with SAS version 8.2 software.

\section{Results}

Raw unadjusted mortality rates for each of the procedures are listed in Table 1. Table 3 shows patient characteristics in the overall group and also for the elective and acute presentation subgroups. In general, acute patients had a higher incidence of adverse risk factors and, overall, were sicker on admission. In Table 4 outcome variables are presented in 3 ways. First, unadjusted mortality rates are given for each subpopulation defined by the explanatory variables. The univariable magnitude of effect of a given risk factor on raw mortality is evident. Then adjusted mortality differences are presented, examining the effect of the variable under consideration, with the others held fixed. This is important, for example, because one variable (eg, acute presentation) often is associated with a higher incidence of other adverse risk factors, such as advanced age or comorbidities. Finally, the ORs quantify the relative effects of each independent variable on mortality within the multivariable logistic regression model. With the large sample size, virtually all variables are highly statistically significant, but using adjusted risk differences and ORs, relative magnitudes are more easily assessed. The $\mathrm{C}$ statistic of the model was 0.735 , indicating high predictive power.

Of baseline characteristics, acute presentation proved to be the most important determinant of mortality, and the incidence appeared to accelerate over time (Figure 1). Acute 
TABLE 4. Effects of baseline variables on outcome

\begin{tabular}{|c|c|c|c|c|c|c|c|c|}
\hline Variable & $\begin{array}{l}\text { Unadjusted } \\
\text { mortality } \\
(\%)\end{array}$ & $\begin{array}{c}\text { Unadjusted } \\
\text { mortality } \\
\text { difference }\end{array}$ & $\begin{array}{c}\text { Adjusted } \\
\text { mortality } \\
(\%)\end{array}$ & $\begin{array}{c}\text { Adjusted } \\
\text { mortality } \\
\text { difference }\end{array}$ & Adjusted odds ratio & $x^{2}$ & $\begin{array}{l}\text { Parameter } \\
\text { estimate }\end{array}$ & $P$ value \\
\hline Acute presentation & 12.9 & - & 10.7 & - & 2.11 & 3244 & 0.7445 & $<.001$ \\
\hline Elective & 5.1 & 7.8 & 5.5 & 5.2 & & & & \\
\hline Age $\geq 70 y$ & 9.4 & - & 9.1 & - & 1.88 & 2150 & 0.6322 & $<.001$ \\
\hline Age $<70 y$ & 5.0 & 4.4 & 5.2 & 3.9 & & & & \\
\hline Reoperation, yes & 11.3 & - & 9.7 & - & 1.61 & 1123 & 0.4762 & $<.001$ \\
\hline Reoperation, no & 6.2 & 5.1 & 6.4 & 3.3 & & & & \\
\hline Endocarditis, yes & 10.6 & - & 10.3 & - & 1.59 & 338 & 0.4614 & $<.001$ \\
\hline Endocarditis, no & 6.9 & 3.7 & 7.0 & 3.3 & & & & \\
\hline CAD, yes & 9.3 & - & 8.4 & - & 1.58 & 1024 & 0.4552 & $<.001$ \\
\hline CAD, no & 5.0 & 4.3 & 5.6 & 2.8 & & & & \\
\hline Valve replacement & 7.2 & - & 7.4 & - & 1.52 & 408 & 0.4158 & $<.001$ \\
\hline Valve repair & 6.8 & 0.4 & 5.1 & 2.3 & & & & \\
\hline CHF, yes & 10.5 & - & 8.3 & - & 1.39 & 605 & 0.3262 & $<.001$ \\
\hline CHF, no & 5.4 & 5.1 & 6.3 & 2.0 & & & & \\
\hline Female gender & 8.4 & - & 8.3 & - & 1.37 & 590 & 0.3139 & $<.001$ \\
\hline Male gender & 6.2 & 2.2 & 6.3 & 1.9 & & & & \\
\hline$E F \geq 0.35$ & 6.6 & - & 6.9 & - & 1.34 & 280 & 0.2944 & $<.001$ \\
\hline $\mathrm{EF}<0.35$ & 11.1 & 4.5 & 8.9 & -2.0 & & & & \\
\hline Year $\geq 1999$ & 6.9 & - & 6.4 & - & 1.34 & 511 & 0.2945 & $<.001$ \\
\hline Year $<1999$ & 7.5 & -0.6 & 8.3 & -1.9 & & & & \\
\hline 0 Comorbidities & 4.5 & - & 5.0 & - & 1.19 & 1586 & 0.1716 & $<.001$ \\
\hline 1 Comorbidity & 5.5 & 1.0 & 5.8 & 0.8 & (Average per comorbidity) & & & \\
\hline 2 Comorbidities & 6.4 & 1.9 & 6.8 & 1.8 & & & & \\
\hline 3 Comorbidities & 8.1 & 3.6 & 7.9 & 2.9 & & & & \\
\hline 4 Comorbidities & 10.5 & 6.0 & 9.1 & 4.1 & & & & \\
\hline Severe Lesion, yes & 6.8 & - & 6.9 & - & 0.83 & 151 & -0.1880 & $<.001$ \\
\hline Severe Lesion, no & 8.4 & -1.6 & 8.1 & -1.2 & & & & \\
\hline Overall & 7.1 & - & 7.1 & - & & & & \\
\hline \multicolumn{9}{|l|}{ Procedures (referenced to AVR) } \\
\hline Aortic root & 11.1 & 5.4 & 13.5 & 7.9 & 2.78 & 650 & 1.0227 & $<.001$ \\
\hline Isolated tricuspid & 10.7 & 5.0 & 11.4 & 5.8 & 2.26 & 199 & 0.8173 & $<.001$ \\
\hline Multiple valve & 11.2 & 5.5 & 10.5 & 4.9 & 2.06 & 1440 & 0.7203 & $<.001$ \\
\hline Isolated mitral & 7.7 & 2.0 & 7.9 & 2.3 & 1.47 & 578 & 0.3880 & $<.001$ \\
\hline Isolated pulmonic & 4.4 & -1.3 & 7.1 & 1.5 & 1.29 & 2 & 0.2556 & .141 \\
\hline Isolated aortic & 5.7 & - & 5.6 & - & 1.00 & - & - & - \\
\hline Concurrent operation, yes & 10.0 & - & 9.9 & - & 1.58 & 736 & 0.4568 & $<.001$ \\
\hline $\begin{array}{l}\text { Concurrent operation, no } \\
\text { (referenced to valve-only } \\
\text { procedure) }\end{array}$ & 6.7 & 3.3 & 6.7 & 3.2 & & & & \\
\hline
\end{tabular}

The regression intercept was -4.3817 . $C A D$, Coronary artery disease; $C H F$, congestive heart failure; $E F$, ejection fraction; $A V R$, aortic valve replacement.

presentation was present in $22.4 \%$ of procedures in 1994 versus $31.7 \%$ in 2003 (a $42 \%$ increase over the decade). To illustrate the effects of acute presentation on mortality, the raw elective mortality was $5.1 \%$ versus $12.9 \%$ for acute presentation (a 253\% increment). Within acute categories, the raw mortality for urgent status was $10.4 \%$, for emergency status was $23.8 \%$, and for salvage status was $44.8 \%$. The next most important variable was advanced age, followed by reoperation, endocarditis, etc. (listed in descending order in Table 1). Patients selected for valve repair generally had better survival than those receiving replacement, and female gender was associated with a higher mortality. Operative results appeared to improve over time, and although the average effect of a single comorbidity was modest, multiple morbidities or specific morbidities, such as renal failure, could produce major effects. Having a hemodynamically severe valve lesion seemed to be protective.

With regard to individual procedures, aortic root reconstruction appeared to have the highest risk, followed by tricuspid valve procedures and multiple valve procedures, 


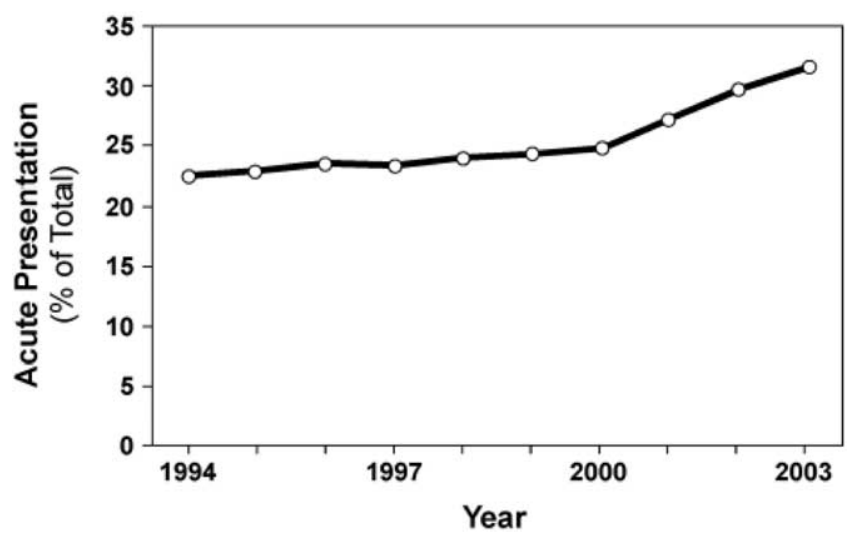

Figure 1. The incidence of acute presentation increased steadily over the decade.

etc. (Table 1). The ORs in this analysis are referenced to the lowest-risk operation, aortic valve procedures. Focusing on root reconstructions $(\mathrm{n}=11,545), 10,724$ were listed as having valve conduits, and 821 had valve-sparing root replacements. Of the entire group, $6044(52 \%)$ were performed for ascending aortic aneurysms, 435 (4\%) for aortic dissections, and 5066 (44\%) had no aortic root pathology documented. The majority of the latter group was listed as having aortic stenosis (42.3\%) and/or aortic insufficiency $(50.7 \%)$ only. In the latter group 2152 patients had stentless porcine or homograft root replacement, 545 had mechanical valve composite grafts, and the remainder had a plethora of other prostheses. The raw mortality for root reconstruction for aortic aneurysms was $10.5 \%$, for aortic dissection was $23.7 \%$, and for root replacement without root pathology was $9.5 \%$. In the valve plus "other" category, 9877 patients had aortic valve and noncomposite ascending aortic replacement procedures, with a raw mortality of $9.2 \%$. In the entire data set, addition of an "other" cardiac or noncardiac operation increased average risk appreciably (Table 1), although there was likely significant variation between "other" categories (Table 2). In the "other" analysis, the OR was referenced to the same valve procedure but without the "other" component. Lastly, the primary causes of death for the study group are shown in Table 5. This primary designation refers to the single problem that initiated the fatal outcome, understanding that additional problems likely occurred during the hospital course. The most important initiating factor was cardiac, followed by pulmonary and neurologic, as listed in Table 5. Also documented are the incidences of complications occurring in the data set. Atrial fibrillation was most common, followed by pulmonary and renal complications, and the remainder are shown in Table 5. In this analysis patients could have more than one complication.

\section{TABLE 5. Causes of mortality and morbidity}

\begin{tabular}{lr} 
Primary cause of mortality & \\
Cardiac & $60.3 \%$ \\
Pulmonary & $8.9 \%$ \\
Neurologic & $8.2 \%$ \\
Infection & $6.4 \%$ \\
Renal & $3.3 \%$ \\
Vascular & $2.0 \%$ \\
Valvular & $1.1 \%$ \\
“Other” & $9.8 \%$ \\
Complications & \\
Atrial fibrillation & $27.0 \%$ \\
Prolonged ventilation & $14.0 \%$ \\
Renal failure & $7.1 \%$ \\
Reoperation for bleeding & $5.5 \%$ \\
Heart block & $5.2 \%$ \\
Pneumonia & $4.5 \%$ \\
Gastrointestinal & $4.3 \%$ \\
Noncardiac reoperation & $3.5 \%$ \\
Cardiac arrest & $3.3 \%$ \\
“Other” cardiac reoperation & $3.1 \%$ \\
Urinary tract infection & $2.9 \%$ \\
Permanent stroke & $2.8 \%$ \\
Septicemia & $2.5 \%$ \\
Multiorgan failure & $2.1 \%$ \\
Anticoagulation complication & $2.0 \%$ \\
Transient stroke & $1.5 \%$ \\
Tamponade & $1.4 \%$ \\
Coma $>24$ h & $1.1 \%$ \\
Leg infection & $1.0 \%$ \\
\hline
\end{tabular}

Other complications occurred in less than $1.0 \%$.

\section{Discussion}

Improvements in cardiac surgery over the past half century at times have been rapid and at others have been slow and incremental. It is reasonable to state, however, that the current aggregate ability to surgically manage heart disease has been one of the medical success stories of all time. The first step in quality improvement is defining a problem area, which requires data collection and analysis, and then strategies are implemented to overcome specific deficiencies. ${ }^{7}$ As a final step, data again are collected to verify the efficacy of therapeutic interventions. Cardiac valve surgery presents special difficulties in following this process. Most studies from single centers have evaluated small series of patients and focused on highly specific subgroups. Often, a center is motivated to publish only good results, so that problem areas can be overlooked. Because outcomes can represent a moving target, assessment over time is important, and confusion has existed regarding patient classification in some categories. Adverse characteristics, such as advanced age, low ejection fraction, hemodynamic severity, and acute presentation, probably affect prognosis more than in coronary surgery, ${ }^{8}$ but the exact magnitudes are unclear. This study was designed to evaluate comprehensively the mor- 
tality characteristics of the entire STS valve surgery database over the past 10 years and potentially to overcome many of the methodologic deficiencies outlined above. The overall goal was to define current problem areas in valve surgery for future innovation and quality improvement. A secondary goal was to better understand how variables interrelate to produce an overall mortality figure.

The most striking problem area in the current analysis was acute presentation. Similar to other studies and with all other variables being constant, acute presentation was associated with a 2-fold increase in operative mortality, which was more than any other risk factor. ${ }^{9-12}$ Less than a quarter were "obligatory" emergencies (eg, acute myocardial infarction, endocarditis, and aortic dissection), so that most might have been candidates for earlier intervention. Although definitive conclusions about the timing of the operation are difficult to make from data such as these, it is plausible that referring patients with significant valve lesions under elective conditions before severe refractory symptoms convert the operation to urgent status could affect overall operative mortality in a positive manner. It is disconcerting that the incidence of acute presentation increased by $42 \%$ over the decade. One could hypothesize that cardiology practice has preferentially emphasized acute coronary disease during this period, and perhaps some of this acute focus has carried over to valvular patients. On the other hand, the concept of earlier referral is now well accepted for mitral regurgitation, and perhaps with documentation of acute presentation risks, a similar principle could be established for all of valve surgery. The best results are obtained with elective referral, and procrastinating until urgent or emergency intervention is required seems to double operative risk.

The other surprising finding of this study was the high relative risk of aortic root replacement. It appeared that this was not due to a predominance of aortic dissections in the population (mortality, 23.7\%) because dissection comprised only $4 \%$ of cases. Although composite aortic valve and ascending aortic replacement for root aneurysm was associated with a $10.5 \%$ mortality and noncomposite replacement had a $9.2 \%$ mortality, all of these results might not be out of line. ${ }^{13-15}$ The high mortality for root replacement for standard aortic valve disease without root pathology, however, deserves special attention. It seemed that almost half of the aortic root reconstructions were performed in the absence of aneurysms, and this might reflect the recent trend toward using freestyle or homograft prostheses as root replacements for isolated aortic valve disease. Although this group comprised less than $3 \%$ of aortic valve procedures (without root pathology), the mortality was close to $10 \%$. It should be emphasized that simple aortic valve replacement in this series was the lowest-risk valve surgery (5.7\% raw mortality) and that standard valve replacement probably should be used preferentially when the root is normal. In fact, most authorities would agree that root replacement should be reserved for patients with complex dissections, annuloaortic ectasia, or true root aneurysms, ${ }^{14,15}$ and the trend toward inappropriate root replacement should be discouraged.

To experienced valve surgeons, it is not surprising that isolated tricuspid valve procedures carried such a high risk. These patients often present with advanced sequelae of chronic systemic venous hypertension, such as liver or renal failure, and can pose difficult management problems. The effects of chronic tricuspid regurgitation can be subtle and insidious, and a message of careful monitoring and early referral for this disorder also would be appropriate. Usually, in any single center only a small number of isolated tricuspid procedures are available for analysis, and this group represents one example for which the STS data set could be useful. It is clear from this study that isolated tricuspid procedures constitute one of the high-risk categories. Multiple valve surgery also is a complex topic. ${ }^{16}$ Each of the different valve combinations likely represents differing pathologies; for example, the aortic-pulmonic valve procedures might be predominantly Ross operations. With such a large number of multiple valve procedures, the STS registry might be uniquely positioned to better understand this diverse topic, and more detailed analyses seem indicated.

This study produced many more questions than it answered. The risk of advanced age is ubiquitous in surgical articles, ${ }^{11,17-19}$ but the importance of reoperation recently has been de-emphasized. ${ }^{9,20-22}$ As the third most important preoperative variable over the past decade, reoperation certainly deserves more careful examination. Perhaps reoperation is of minimal importance for simple isolated procedures, but with more complex lesions (that are less frequently reported), the risk is amplified. Reoperation could be a fruitful topic for future study, including formal analysis of statistical interactions of variables. Similarly, the topics of endocarditis and valve repair versus replacement should be further investigated, as well as that of female gender. As in other studies, ${ }^{23-26}$ coronary disease and LV dysfunction increased risk.

Similar to previous analyses, ${ }^{27}$ adjusted mortality decreased by almost $25 \%$ over the decade, almost certainly because of refinements in surgical technique and postoperative care. Was this a general phenomenon or a specific function of certain procedures? Did the emergence of minimally invasive valve surgery or the increasing use of valve repair contribute to this effect? ${ }^{28-32}$ Parenthetically, and perhaps disturbingly, unadjusted mortality decreased by only $8 \%$. The difference was largely due to increased rates of acute presentation, and reversal of the acute presentation trend could allow relative improvements in valve surgery results to become more evident in everyday practice. Co- 
morbidity effects in this study were assessed in a fairly rudimentary way. It would be useful to apply a weighted comorbidity index to take into account the more pronounced effects of certain comorbidities, such as renal failure. ${ }^{33}$ Finally, hemodynamically severe valve lesions seemed to have a protective effect on operative mortality. Perhaps this finding is a function of immediate and profound hemodynamic improvement postoperatively, although again, further analysis will be required to clarify this point.

One function of a database is to define problem areas so that potential solutions can be considered. It is interesting that cardiac issues remain the initiators of mortality in more than half of operative deaths. Although the exact types of cardiac problems are not documented, one can surmise that low cardiac output or other manifestations of inadequate myocardial protection might still be occurring in some complex valve cases requiring longer clamp times. Cardiac arrhythmias also might be contributing to mortality and constitute the most common complication. Lastly, pulmonary problems remain the most frequent noncardiac cause of morbidity and mortality, ${ }^{34,35}$ and effective innovations in each of these areas will likely produce further improvements in the future.

This attempt at a comprehensive analysis of overall valve surgery mortality should not be construed as a substitute for detailed assessment of individual procedures. Rather, this study poses a different question: What are the aggregate risk factors for all types of valve surgery? With current trends toward publication of overall valve mortality figures from center to center, an improved general understanding of relationships between baseline risk and mortality will be important. ${ }^{36}$ Especially because baseline characteristics influence valve mortality to a greater extent than coronary surgery, further illumination seems indicated. This study can be viewed as a first draft of such an analysis and produced several surprising results. Each of these findings, however, is dependent on the quality of data recording, and coding errors are possible, even though many audits have shown STS data to be very accurate. Other limitations of the data set exist, such as the 5\% of patients listed as having "other" cardiac procedures, the exact nature of which is unknown. Each of these issues is being addressed, and hopefully, the STS database will continue as a prime example of physician-initiated evidence-based medicine.

In conclusion, this study illustrates the power of multicenter collaboration in generating a clinical database in adult cardiac surgery. Complex or unusual valve procedures can be investigated in a valid and comprehensive manner, and concepts can be developed that are difficult to perceive in any single center. A major finding of this study was the high mortality in possibly inappropriate aortic root reconstructions. The data suggest that simple aortic valve replacement (the lowest-risk procedure) should be favored for all but the most compelling aortic root pathology. Finally, the most important observations of this study are the accelerating trend toward acute presentation over the past decade and the primary importance of this variable in increasing operative risk. Cardiac clinicians should redouble their efforts to emphasize earlier surgical referral for all types of severe valve lesions before urgent or emergency intervention is required.

\section{References}

1. Glower DD, Tuttle RH, Shaw LK, Orozco RE, Rankin JS. Current prognosis of ischemic mitral regurgitation managed by routine mitral valve repair. J Thorac Cardiovasc Surg. 2005;129:860-8.

2. Edwards FH, Grover FL, Shroyer AL, et al. The Society of Thoracic Surgeons National Cardiac Surgery Database: current risk assessment. Ann Thorac Surg. 1997;63:903-8.

3. Edwards FH, Clark RE, Schwartz M. Practical considerations in the management of large multi-institutional databases. Ann Thorac Surg. 1994;58:1841-4.

4. Grover FL, Edwards C. Similarity between the STS and New York State databases for valvular heart disease. Ann Thorac Surg. 2000;70: 1143-4.

5. Karthik S, Srinivasan AK, Grayson AD, Limitations of additive EuroSCORE for measuring risk stratified mortality in combined coronary and valve surgery. Eur J Cardiothorac Surg. 2004;26:318-22.

6. Caus T, Calon D, Collart F, et al. Parsonnet's risk score predicts late survival but not late functional results after aortic valve replacement in octogenarians. J Heart Valve Dis. 2002;11:498-503.

7. Grover FL, Cleveland JC Jr, Shroyer LW. Quality improvement in cardiac care. Arch Surg. 2002;137:28-36.

8. Gardner SC, Grunwald GK, Rumsfeld JS, et al. Comparison of shortterm mortality risk factors for valve replacement versus coronary artery bypass graft surgery. Ann Thorac Surg. 2004;77:549-56.

9. Jamieson WR, Burr LH, Miyagishima RT, et al. Re-operation for bioprosthetic aortic structural failure-risk assessment. Eur J Cardiothorac Surg. 2003;24:873-8.

10. Bech-Hanssen O, Ryden T, Schersten H, et al. Mortality after mitral regurgitation surgery: importance of clinical and echocardiographic variables. Eur J Cardiothorac Surg. 2003;24:723-30.

11. Bridges CR, Edwards FH, Peterson ED, et al. Cardiac surgery in nonagenarians and centenarians. J Am Coll Surg. 2003;197:347-57.

12. Beghi $\mathrm{C}$, De Cicco G, Nicolini F, et al. Cardiac valve reoperations: analysis of operative risk factors in 154 patients. J Heart Valve Dis. 2002;11:258-62.

13. Tan ME, Dossche KM, Morshuis WJ, et al. Operative risk factors of type A aortic dissection: analysis of 252 consecutive patients. Cardiovasc Surg. 2003;11:277-85.

14. Sioris T, David TE, Ivanov J, et al. Clinical outcomes after separate and composite replacement of the aortic valve and ascending aorta. J Thorac Cardiovasc Surg. 2004;128:260-5.

15. Bach DS, Cartier PC, Kon ND, et al. Impact of implant technique following freestyle stentless aortic valve replacement. Ann Thorac Surg. 2002;74:1107-13.

16. Remadi JP, Baron O, Tribouilloy C, et al. Bivalvular mechanical mitral-aortic valve replacement in 254 patients: long-term results-a 22-year follow-up. Ann Thorac Surg. 2003;76:487-92.

17. Davis WJ 3rd, Vaynblat M, Chiavarelli M, et al. Open heart surgery in patients 85 years and older. J Card Surg. 2004;19:7-11.

18. Edwards MB, Taylor KM. Outcomes in nonagenarians after heart valve replacement operation. Ann Thorac Surg. 2003;75:830-4.

19. Mehta RH, Eagle KA, Coombs LP, et al. Influence of age on outcomes in patients undergoing mitral valve replacement. Ann Thorac Surg. 2002;74:1459-67.

20. Potter DD, Sundt TM 3rd, Zehr KJ, et al. Operative risk of reoperative aortic valve replacement. J Thorac Cardiovasc Surg. 2005;129:94-103. 
21. Akins CW, Hilgenberg AD, Vlahakes GJ, et al. Aortic valve replacement in patients with previous cardiac surgery. J Card Surg. 2004;19: $308-12$.

22. Borger MA, Yau TM, Rao V, et al. Reoperative mitral valve replacement: importance of preservation of the subvalvular apparatus. Ann Thorac Surg. 2002;74:1482-7.

23. Talwalkar NG, Earle NR, Earle EA, et al. Mitral valve repair in patients with low left ventricular ejection fractions: early and late results. Chest. 2004;126:709-15.

24. Kasimir MT, Bialy J, Moidl R, et al. EuroSCORE predicts mid-term outcome after combined valve and coronary bypass surgery. $J$ Heart Valve Dis. 2004;13:439-43.

25. Sharony R, Grossi EA, Saunders PC, et al. Aortic valve replacement in patients with impaired ventricular function. Ann Thorac Surg. 2003; 75:1808-14.

26. Szalay ZA, Civelek A, Hohe S, et al. Mitral annuloplasty in patients with ischemic versus dilated cardiomyopathy. Eur J Cardiothorac Surg. 2003;23:567-72.

27. Goodney PP, Siewers AE, Stukel TA, et al. Is surgery getting safer? National trends in operative mortality. J Am Coll Surg. 2002;195:219-27.

28. Rankin JS, Livesey SA, Smith LR, et al. Trends in the surgical treatment of ischemic mitral regurgitation: effects of mitral valve repair on hospital mortality. Semin Thorac Cardiovasc Surg. 1989;1:149-63.

29. Gillinov AM, Wierup PN, Blackstone EH, et al. Is repair preferable to replacement for ischemic mitral regurgitation? J Thorac Cardiovasc Surg. 2001;122:1125-41.

30. Mihaljevie T, Cohn LH, Unic D, et al. One thousand minimally invasive valve operations: early and late results. Ann Surg. 2004;240: 529-34

31. Glower DD, Siegel LC, Frischmeyer KJ, et al. Predictors of outcome in a multicenter port-access valve registry. Ann Thorac Surg. 2000; 70:1054-9.

32. Chitwood WR Jr, Wixon CL, Elbeery JR, et al. Video assisted minimally invasive mitral valve surgery. J Thorac Cardiovasc Surg. 1997; 114:773-82.

33. Abramov D, Tamariz M, Fremes S, et al. Impact of preoperative renal dysfunction on cardiac surgery results. Asian Cardiovasc Thorac Ann. 2003;11:42-7.

34. Rankin JS, Orozco RE, Rodgers TL, et al. Several new considerations in mitral valve repair. J Heart Valve Dis. 2004;13:399-409.

35. Peterson ED, Coombs LP, Ferguson TB, et al. hospital variability in length of stay after coronary artery bypass surgery: results from the Society of Thoracic Surgeon's National Cardiac Database. Ann Thorac Surg. 2002;74:464-73.

36. Ambler G, Omar RZ, Royston P, et al. Generic, simple risk stratification model for heart valve surgery. Circulation. 2005;112:224-31.

\section{Discussion}

Dr James I. Fann (Stanford, Calif). Scott, you and your colleagues have performed a comprehensive analysis of the determinants of operative mortality in patients undergoing valve surgery using what has become a tremendous resource, the STS database. The importance of this study is that it is an unbiased look at a group of more than 400,000 patients over a 10 -year period. Although this is a retrospective analysis and in a somewhat selected group of patients, it is perhaps the most reliable statistical analysis to date directed at independent risk factors in patients undergoing valve surgery. As you mentioned, this analysis is important because it is not subject to sampling bias or the results of a single center or surgeon. It does not focus on one specific procedure and is not compiled over an inordinately long period of time.

In this study acute presentation was the most important risk factor for operative mortality. This variable is well recognized in its association with a worse outcome, and you mentioned that it is important to refer patients with severe valve lesions under elective and not emergency conditions. What is more important is the underlying problem that caused the patient to present acutely. My first question is this: How did these acute or emergency patients present? As background, I notice that $14 \%$ of the patients in the acute category were operated on for emergency or salvage indications, whereas the other $85 \%$ were in the urgent subgroup. Were the emergency and salvage patients with operative mortality rates of $24 \%$ and $45 \%$, respectively, patients presenting with acute myocardial infarction, congestive heart failure, and/or endocarditis, because these are significant risk factors that you mentioned, and they also are variables that might not be directly affected by earlier valvular intervention?

Dr Rankin. Thank you, Jim, and I would like to also first recognize the many individuals who have contributed to the development of the STS database, many of whom are in this room. As you said, this has become an important resource for all of us; it was quite a good idea.

It is clear that the acute presentation group is a heterogeneous group, and there are patients with, let us say, obligatory acute presentation (eg, aortic dissections and endocarditis) that are at higher risk and require operations with no opportunity for intervention. But if we look at the overall numbers of those patients, they are the minority, accounting for less than a fourth of the population. The majority of patients are potential candidates for earlier referral. If we correlate to our own clinical practices, I think we have seen in recent years that patients are being referred later, perhaps "worked up a year ago, decided against surgery," and then a year later, all of a sudden they are in the hospital with pulmonary edema requiring an emergency operation. Therefore I think there is probably a definite majority of the acute presentation patients who might have been evaluated earlier and perhaps could have been operated on earlier. It has been so successful in mitral valve repair to convince the cardiologists to refer the patients earlier, and earlier referral has really improved the outcomes. I think we now need to extend that concept to all of valvular surgery: if a patient has a severe valve lesion, there is really no advantage to waiting.

Dr Fann. Just as interesting is your finding that aortic root reconstruction was the highest-risk procedure, with an OR of more than 2.7 referenced to aortic valve replacement. What is important to realize is that in this group, 5066 patients had no aortic root pathology, and more than 2100 of them had a stentless porcine or homograft root replacement. The mortality for reconstruction without root pathology is more than $9 \%$. Your conclusion that root replacement should be considered only for specific root pathology needs to be emphasized. There are numerous reports of substantially lower operative mortality rates than what was found in the series of patients undergoing stentless valve implant. Why do you think that the operative mortality rate in this group is so much higher than the rate that has been reported, other than a mere reality check?

Dr Rankin. I think it is also important to emphasize that there is no such thing as perfect methodology in clinical research. In some ways, if I present a series of 120 mitral valve repairs, advantages exist, because I took care of all those patients. I really knew everything that happened with them, but the disadvantage is the small sample size. Here we have the opposite extreme, a large sample size as an advantage but a large distance from these patients as a disadvantage, and we do not quite understand what was going on with all of them or what the exact pathology was. But there is a definite suggestion in these data that there are a lot of 
patients now undergoing root replacement with no root pathology, and I think this correlates with some of the articles describing freestyle root replacement as a routine. The STS data suggest that, in the national data set with the real world of all the surgeons doing this in the country, the mortality with this approach is higher than we might think. Given this information, it seems prudent to consider going back to performing just simple aortic valve replacement in these patients.

Dr Fann. Reoperation was a risk factor for operative mortality, with an OR of 1.61. Interestingly, it also comprised a statistically higher proportion of patients in the nonelective category. One question is, how do you define reoperation? Is it redo sternotomy or reoperation for a degenerated or otherwise dysfunctional valve? If it is the latter, and based on the data presented, do you personally think that the argument for placing a bioprosthesis to avoid thromboembolic and anticoagulation-related complications in the younger patient with the intention of future reoperation is justified?

Dr Rankin. Well, I will go back to say that we are in the early stages of looking at the entire data set, and it was a bit of a surprise to us to see that reoperation was so important. I would suggest that any of you who are interested turn in a proposal to the STS publications committee to study the reoperation factor as determining operative mortality - we need to get into those data more. The definition was any previous sternotomy, coronary bypass or valve. Now this finding does not correlate well with all of our articles in the current literature examining isolated aortic or mitral valve procedures in which reoperation is no longer a risk factor. My personal bias is that the reoperation risk probably is related more to the multiple valve procedures and that reoperation be- comes much more important when we get into the more complex operations. I think this is something that needs to be addressed.

Dr Fann. One group of patients that warrants further investigation is comprised of those who underwent mitral valve procedures. Dr Glower and you have previously reported that survival after mitral valve repair for ischemic mitral regurgitation is more influenced by patient characteristics and comorbidity than by the ischemic cause of mitral regurgitation. What was important in that study was the consistent surgical techniques and the undersizing of the annuloplasty ring. In the current study the presence of coronary artery disease was a significant independent risk factor for operative mortality. Do you think that this finding is suggestive that patients who undergo surgical intervention for ischemic mitral regurgitation do worse in terms of operative outcome regardless of comorbidity?

Dr Rankin. One of the problems in the STS data set is that there are a handful of definitions that are lacking. For example, cause of valve disease is not recorded, and therefore it is difficult to say much about ischemic mitral regurgitation. One thing that is clear, however, from Don's recent article, the recent Cleveland Clinic article, and David Adams' work is that the results with routine repair in ischemic mitral regurgitation are a lot better now. Ischemic cause, per se, is likely not a prominent risk factor. The other general impression that is evident in the national cardiac surgery data set is that the quality of cardiac surgery throughout the United States is at an extremely high level. If we look at average mortalities for any procedure and so on, they are only a couple points higher than the very best ones reported in the literature, and therefore I think we can all be proud of our specialty and what has happened over the past decades.

\section{The Journal of Thoracic and Cardiovascular Surgery Conflict of Interest Policy}

To assure fairness to authors submitting work for consideration in The Journal of Thoracic and Cardiovascular Surgery, a mechanism exists for managing conflicts of interest. The editor and each of the section editors complete a "Conflict of Interest" form that identifies any and all relationships with commercial and other academic entities. When the editor has a potential conflict because of a relationship with another entity or author, the editor appoints an alternate editor from among the section editors or editorial board members who assumes the entire responsibility for final decisions on the manuscript in question. The editor does not read the reviews that are submitted nor engage in discussing the manuscript prior to the final decision. When the conflict of interest involves a section editor, a "guest section editor" is appointed who fills the role normally played by the conflicted section editor. All members of the editorial board and reviewers are asked to indicate any conflict of interest when they agree to review a manuscript. 